\title{
Altered Hypothalamic-Pituitary-Adrenal Axis Activity in Patients with Chronic Heart Failure
}

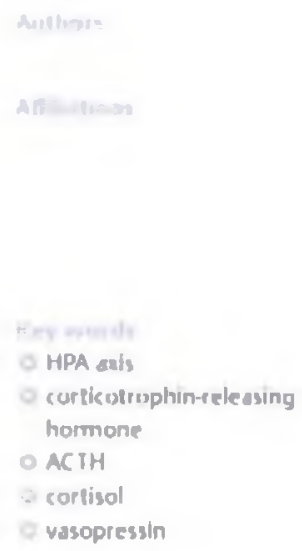

Abstract

A

Neuroendocrine factors play an important role in the pathogenesis of chronic heart falure. Despite numerous clinical and experimental studies, the role of the hypothalamic-pituitary-adrenal axis and glucocorticoid hormones is not fully characterised. Here we present a study of plasma cortisol concentration in 74 chronic heart failure patients, divided into four groups based on NYHA functional classes I-IV, and in 17 control subjects. In parallel, we performed morphological analysis of the hypothalamic-pituitary-adrenal axis components from 8 male patients who had died from chronic heart failure, and 9 male controls. In our study we applied immunohistochemical method and quantitative analysis to investigate an expression of hypothalamic neurohormones (corticotropin-releasing hormone, vasopressin) and adrenocorticotropin hormone in the pituitary. as well as performed general histological examination of the adrenal cortex. Measurement

\section{Inerodustion}

r

Chronic heart failure (CHF) is a widely distributed disorder, expected to become even more prevalent in the near furure because of the aging of the population [1]. According to the neurohormonal hypothesis [2], CHF is considered now as a highly complex clinical syndrome, and its manifestation and progress are strongly dependent on the activation of hormones and cytokines ( $|3|$ and references cited therein). Various neuroendocrine factors, such as norepinephrine, angiorensin II. rennin. and endothetin are strongly

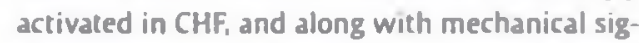
nals they cause an increase in myocyte size and hypertrophy of the heart ( $|4|$ and references cited therein). Vasopressin (VP) was also considered as an important neuroendocrine pathogenetic factor of CHF. VP is synthesized mainly in magnocel- of morning cortisol concentration in plasma of chronic heart failure patients revealed neithet difference compared to controls nor with the severity of the disease. Despite this. a two-fold increase in the density of corticotropin-releasing hormone-immunoreactive neurons as well as a two-fold increase in the number of corticotro. pin-releasing hormone neurons co-expressing vasopressin in the hypothalamic paraventricular nucleus were found. In the anterior pituitary the density of adrenocorticotropin hormone-immunoreactive cells was significantly increased. General histological analysis of the adrenal cortex revealed a drastic thinning of the zona fasciculata and dystrophic changes in corticocyles. Struclural changes, observed in the adrenal cortex. suggest a relative glucocorticoid deficiency. which may coneribute to corticotropin-releasing hormone and adrenocorticotropin hormone upregulation in hypothalamus and pituitary of chronic heart failure patients.

lular hypothalamic nuclei and released into peripheral blood circuitry from the posterior pituitary lobe. However. VP is also produced by parvocellular neurons in the paraventricular nucleus (PVN) (for review, see [5]), where VP colocalizes with corticotropin-releasing hormone (CRH) and potentiates effects of CRH on pituitary corticotrophs, especially under chronic stress situation [6, 7].

Despite the fact that the role of several neuroendocrine systems has been extensively studied in CHF patients. the contribution of the hypothalamic-pituitary-adrenal (HPA) axis to the pathogenesis of CHF is not fully understood. The HPA axis is the key biological machinery, which is primarily activated in response lo stress and regulated in a hierarchical manner via positive and negative feedback mechanisms $|8|$. With respect 
to CHF, the literature on the activity of the HPA axis is controversial: measurement of cortisol in the plasma of CHF patients revealed either normal concentrations $\mid 9,10]$, decreased $|11,12|$, or increased levels $[13,14]$. However, recent comprehensive study [15] performed on a total of 300 patients afflicted by CHF of New York Heart Association functional classes III or IV or systolic heart failure showed that all these patients have a normal range of plasma cortisol levels comparable to those in healthy individuals [16]. Nevertheless, higher plasma corfisol (within in a normal range of cortisol concentrations) had a posirive correlation with higher mortality risk in CHF patients [15]. The pituitary function of CHF patients has been examined by only one group [17], which showed elevated adrenocorticotropin hormone (ACTH) levels in the plasma. While the responses of pituitary to CRH as well as the basal activity of CRH neurons in the hypothalamic PVN have not been studied in CHF patients. evidence from animal models of CHF strongly suggested an upregulation of CRH expression [18, 19).

The aim of the present work was the analysis of plasma cortisol concentrations in CHF parients combined with posimortem morphological examinations of hypothalami, pituitary, and adrenal glands. In the course of this study we found no changes in cortisol plasma concentration in CHF patients, even with severe form [III, IV functional classes, according to the New York Heart Association (NYHA) criteria], which was accompanied by dystrophic changes in the adrenal cortex. These findings coincided with a profound increase of CRH expression in the hypothalamus and ACTH expression in the pituitary. suggesting a disbalance in feed-back signalling in the HPA axis of CHF patients.

\section{Matorials and Methods \\ 7 \\ Merisurement of plasma cortisol cortsartiations}

Seventy-four patients of both genders $(41$ males and 33 females). ranging in age from $32-88$ years ( $64.8 \pm 11.5$ years) were divided into groups based on functional classes (I: 4 parients; II: 19 patients; III: 23 patients: IV: 28 patients) of CHF according to the NYHA criteria. Patients with myocardial infarction within the previous 12 months were excluded. The cont rol group contained blood samples from 17 individuals ( 8 males and 9 females: age ranging from 45 to 68 years; mean age 60.814 .98 years) wit hout known neurological. psychiatric or endocrinological diseases. These patients had initial signs of CHF, such as slight dyspnoea during physical activity. but did not have other symptoms to assess any stage of CHF. Blood samples from all patients were collected at the same time in the morning (8-10AM). Plasma cortisol levels were measured by enzyme immunoassays (DRG Cortisol ELISA Kit. DRG International. Inc., Mountainside. NJ. USA). Written informed consent was obtained from all patients before the study. The study was in agreement with the guidelines approved by the ethics committee of the Russian State Medical University (Moscow, Russia).

\section{Fustinomem moegheílogicei study$$
\text { Pisvce idatlectuon }
$$

Brains from patients were obtained according to the Russian law at autopsy from the Regional Medical Expert Bureau of Medical Legal Examination (Kaliningrad, Russia) and from an Emergency
Hospital (Kursk. Russia). Some samples of adrenal glands were obtained from Department of Pathology (Bureau of Pathological Anatomy). Regional Hospital (Belgorod, Russia). The study was approved by the Local Exhics Committee of Friedrich-Schiller University, Jena. Cermany (Protocol 2387-09/08). Brains from eight male patients who had CHF, ranging in age from 35-65 years ( $53.8 \pm 9.3$ years), were obtained at autopsy. In all cases CHF was verified clinically and/or by autopsy by several pathological criteria: hypertrophy and lipomatosis of the myocardium with dilated heart chambers: local hypertrophy, dyserophy, or atrophy of cardiomyocytes with their lysis and subsequent cardiosclerosis; injuries of blood capillaries with an increase of the wall thickness; and activation of fibroblasts. Patients had died from acute heart or respiratory failure (acute cardiovascular insufficiency). The control group contained samples of brains from nine male individuals, ranging in age from $36-70$ years ( $54.6 \pm 11.8$ years), without known primary neurological or psychiatric conditions and endocrinological pathology who died from non-CHF related causes: acute biain stroke (3), diseases of the respiratory system (2), acute surgical pathology (2), asphyxia (1). and traumatic injury (1). Postmortem time was $15.8 \pm 6.4 \mathrm{~h}$ in controls and $22.5 \pm 11.7 \mathrm{~h}$ in CHF group. Tissue preparalion was performed as described [20]. Briefly, hypothalami, pituitary and adrenal glands were fixed by immersion in $4 x$ paraformaldehyde in phosphate-buffered saline (PBS. pH 7.4) at room temperature for about 2 months. Tissue samples were dehydrated in graded ethanol, embedded in parafin. cut into serial 6-8 $4 \mathrm{~m}$ coronal or horizontal sections and collecied on a series of 10 Superfrost Plus glass slides (Roth. Karlsruhe. Germany).

\section{Iminumghisochemitry}

Consecutive sections of pituitaries and hypothalami containing PVN were stained with antibodies atainst ACTH or CRH as described [20], Briefly, after deparaffinisation and rehydiatıon. sections were incubated in phosphate-buffered saline (PBS) containing $10 \%$ methanol and $3 \%$ hydrogen peroxide. After preincubation with $0.05 \%$ Triton $\times 100$-PBS containing $5 \%$ normal goat serum (PBS-NCS), sections were incubated overnight with one of the primary rabbit polyclonal antibodies - anti-CRH (1:1000, Peninsula Labs Inc.) or anti-ACTH (1:200, Chemicon International. CA, USA) in working solution (WS: $1 \%$ NCS, $0.05 \%$ Triton on PBS. pH 7.4). Then sections were washed with PBS and incubated in WS with biotinylated goat ant 1 -rabbit $\lg C$ ( $1: 200$, Vector Elite kit. Vector Laboratories, Inc. Burlingame, CA. USA). After washing with PBS, ABC complex (Vector Laboratories, CA, USA) in PBS was applied. The reaction was visualised with diaminobenzidine (DAB. Sigma) and $\mathrm{H}_{2} \mathrm{O}_{2}$ in PBS. After rinsing with distilled water, sections were dehydrated in ethanol. cleared in xylene and mounted with embedding medium (Entellan, Merck. Rahway, NJ, USA). For control incubations we used NCS, diluted 10 1:1 000 in PBS-Triton $X$ instead of the primary antibodies. Sections of adrenal glands were stained with hematoxylin-eosin as described [20|. To evaluate co-localization of CRH with VP double fluorescent immunostainings were performed Slides were preincubated with $1 \%$ Triton X 100-P85 containing 10\% NCS and then with the mixture of the primary antibodies: rabbit polyclonal anti-CRH; Peninsula Labs Inc. 1:200 and mouse monoclonal PS41 anti-VP, 1:100, provided by Dr. Harold Gainer |21.22|. dissolved in $0.5 \%$ Triton $\times 100-$ PBS cont aining $1 \%$ NCS (WS). Immunosignals for CRH and VP were visualised by a Cy3-conjugaled goat anti-rabbit and a FITC-conjugated goat anti-mouse IgC (1:100 in WS. Dianova.). Sections were mounted with antifading 
medium (Fluoromount C. Southern Biotechnology Associates, Biozol, Eching, Germany).

\section{Semsiquaren hitive altalysis}

Counting of CRH-positive neurons was performed on an Axioskop microscope [Zeiss, Oberkochen, Germany] equipped with a motorised stage and Neurolucida software-controlled computer system (MicroBrightField Europe, Magdeburg. Cermany). The contours of the PVN field occupied by CRH-positive neurons were outlined manually with the cursor using a 5 x objective (Plan-Neofluar') All immunopositive neurons containing a nucleus and clearly distinguishable from background within the selected area were counted using a 20 nobjective [23]. Cells were labeled by a symbol and their numbers as well as an outlined area were estimated automatically. Finally. cell profile densities (numbers of cell profiles per unit area) of CRH-positive cells in each subject were calculated based on the total number of counted neurons in the sample and the estimated sample area [24]. Additionally, average nearest neighbour distances between immunolabeled neurons were calculated using Neuroexplorer software (MicroBrightField Europe, Magdeburg. Cermany). At least three hypothalamic sections from each subject were analysed.

Counting of double-labeled CRH/VP neurons was performed on the digital images of the immunostained sections obtained with a confocal laser scanning microscope TCS SP5 (Leica, 20 × objective, $1024 \times 1024$ pixels resolution) using the "Image Tool 2.0" software. Stacks of images of $1 \mu \mathrm{m}$ thickness were obtained from different parts of the PVN in sections double-stained for CRH and VP. Then. the three-dimensional reconstruction of the $Z$ series was performed to assess an overlap between CRH and VP for confirmation of co-localized immunoproducts. The total number of CRH-positive neurons and the number of CRH neurons immunopositive for VP were counted. Then the percentage of single and double-labeled CRH-positive cells was calculated. All counts were blindly performed on coded preparations by the same investigator.

Counting of ACTH-labeled cells in the anterior lobe of pituitary was performed on the digital images of the immunostained sections obtained with a digital camera "Olympus DP10" with the "DP-Soft 3.0" software (20 x objective) using the "Image Tool 2.0" softwane (University of Texas Health Science Center. San Antonio, Texas). The number of all immunopositive cells within the defined area $(100 \mu m \times 100 \mu \mathrm{m})$ was estimated and then the cell profile density was calculated. From each subject nine fields were analysed in three sections.

\section{Phetcorationical docenimentastion}

Immunohistochemically stained sections with DAB visualisation of final products were examined with an "Olympus BX50" microscope. An "Olympus DP10" digital camera with "DP Soft $3.0^{\circ}$ software was used for micropholography. Digital images were adjusted for contrast and brightness in "Adobe Photoshop" (Adobe Systems, version 8.0.1).

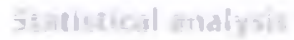

$\nabla$

The differences in blood cortisol concentrations were analysed by one-way analysis of variance (ANOVA) for repeated measures using the online program http://faculty.vassar.edu. Two-tailed parametric test (t-test) was applied to evaluate the morphologi- cal data using "MS Excel-7.0" tool. All results are presented as a group mean values with standard deviation (SD). The accepted level of significance was $5 \%$

\section{Result:

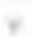 \\ Placena cirrusol concenfrafions}

Measurement of total plasma cortisol revealed no significant sex differences either in controls $(138.38 \pm 36.65 \mathrm{ng} / \mathrm{ml}$, males and $148.62 \pm 41.79 \mathrm{ng} / \mathrm{ml}$, females) or CHF patients ( $130.09 \pm 59.52 \mathrm{ng}$ ) $\mathrm{ml}$ and $132.16 \pm 49.38 \mathrm{ng} / \mathrm{ml}$, in males and females, respectively: values in patients of different functional classes of CHF were pooled). Comparison of cortisol levels between controls and CHF patients revealed no significant difference $[143.8 \pm 41.01 \mathrm{ng} / \mathrm{ml}$. controls and $131.01 \pm 55.24 \mathrm{ng} / \mathrm{ml}$. CHF patients). There were no significant changes in cortisol levels between the groups of CHF patients divided into four functional classes of CHF according to the NYHA classification ( $121.28 \pm 21.96 \mathrm{ng} / \mathrm{ml}, 121.55 \pm 46.05 \mathrm{ng}$ ) $\mathrm{ml}, 122.43 \pm 38.2 \mathrm{ng} / \mathrm{ml}$ and $145.88 \pm 70.72 \mathrm{ng} / \mathrm{ml}$, in patients with I, II, III. and IV functional class of CHF, respectively).

\section{CRH neurors}

$\nabla$

In the PVN of control patients small and medium sized CRH-positive neurons were located along the third ventricle (O Fig. IA). The intensity of CRH-staining varied from poor to very strong. but weakly and moderately stained cells prevailed ( Fig. IC). In CHF patients, the population of CRH-positive neurons in the PVN was much larger in comparison with the control group (a Fig. IB). CRH-immunoreactivity (IR) appeared as clear homogeneous cytoplasmic staining pattern. Most CRHpositive perikarya as well as their processes were intensively stained (D Fig. 10). Results of the quantitative analysis indicate that the profile density of CRH-positive neurons in the PVN is significantly increased in CHF patients ( $+70 \%$; p $<0.05$. 8-tes ) ), as shown in 0 Fg. 1E. A nearest neighbour distance analysis was also performed to obtain insight into the spatial distribution of CRH-labeled neurons. The average nearest neighbour distance between CRH-positive cell profiles in PVN was significantly smaller in CHF patients $(-21 \%, p<0.05$, $t$-test, $\circ$ Fig. IF). This finding correlates well with the estimates of cell profile density (a Fig. IE), in order to evaluate co-expression of CRH and VP in the same neurons we performed double immunofluorescent staining ( 0 Fig. 2). As indicated in the graph (o Fig. 2C), CRH-IR was found in $24.9 \pm 2.6 \%$ of the VP-positive neurons in controls (a Fig. 2A), In CHF patients, the proportion of double-labeled neurons was increased almost two-fold as compared with the controls ( $\%$ Flg. 28, C).

\section{Antorsor pituitary}

$\nabla$

In cells of the anterior lobe of pituitary ACTH-IR was found as a homogenous cytoplasmic staining pattern. The intensity of the IR signal was much more pronounced in patients with CHF as compared with the controls (data not shown). Semiquantitative analysis revealed a significant increase $(+41 \%, p<0.001)$ in relative density of ACTH-positive cells in the anterior lobe of patients afflicted with CHF. 


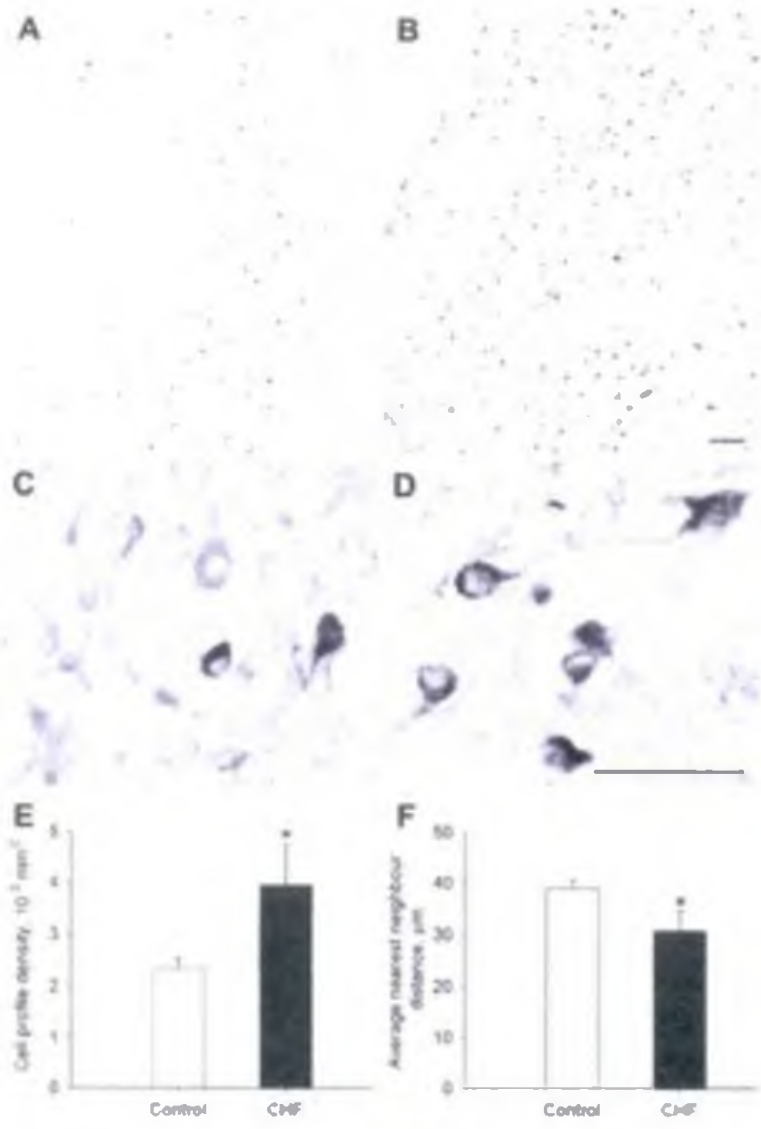

(15. I Incressed CRIHmmunoreactivity in parvocellular neurons of the IVN in CMI padents. A C CRM-positive neurons in a 64year ald control puthent. at small (A) and big (C) magnifications. B. D: Numerous intensively stained CRHpositue neurons in the PVN of a 65-year ofd patient afficted with the CMr, at small (B) and big (D) magnifications. Immunohistochemical staining with anti-CRH antibodies. developed

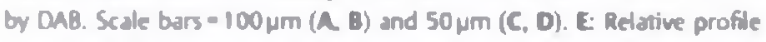
density of CRH-positive cells Is significantly higher in CHF group than in controls. $F$ : The average nearest neighbour distance between CRH. positive cell profiles in PVNis significantly smaller in CHF patients. Croup mean values of the parameters are calculated from indivdual mean values. "pe 005 (t-test)

\section{Aide wholl ces: $:-3$}

In CHF patients we observed drastic thinning. plethora and diapedesis of the zona fasciculata as well as a discomplexation of the zona glomerulosa (o Fig. 3B), as compared with controls ( Fig. 3A). Detailed examination of the zona fasciculata revealed a profound vacuolated dystrophy ( $\mathrm{Fig} .3 \mathrm{C}$ ), pyknosis ( Fig. 3C. O) and delipidation of corticocytes in the presence of erythrostasis ( Fig. 30).

\section{Coverisolon}

$\checkmark$

The measurement of CRH-IR in the postmortem hypothalami has been performed previously by several groups, which showed reliable changes of hypothalamic CRH expression in several human diseases such as depression [25|, multiple sclerosis [26]. hypertension $[23,27]$, and alcoholic disease [20]. Moieover.
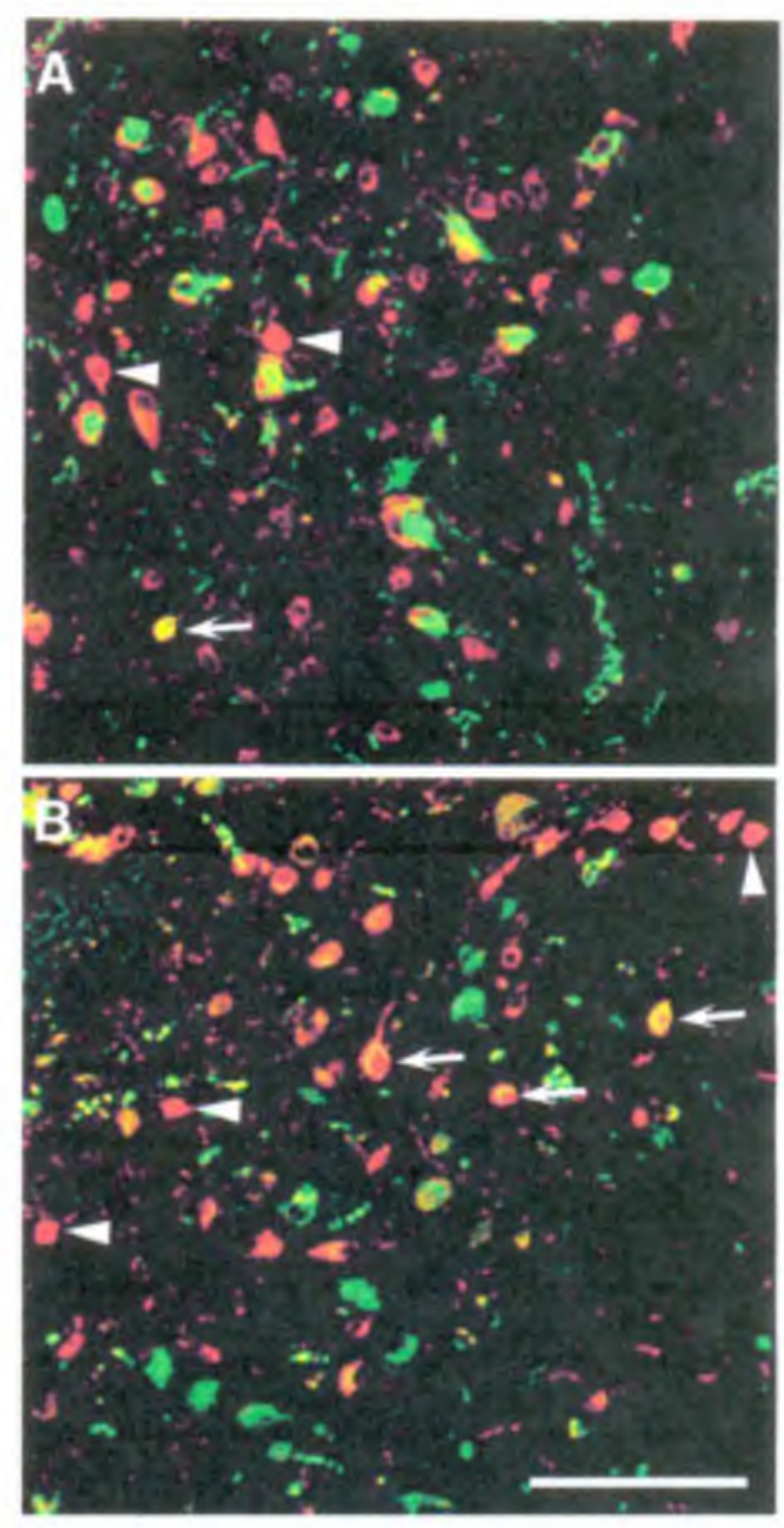

Fig. 2 Increased VPimmunoreactivity in CRH neurons of CMF patdents A. Fragment of the hypothalamic PVN of the 64-vear old control and 62 year dd CHF patients (B). Immunohistochemical double staining with rabbit ank-CRH and mouse anti-YP antibodies visualised with huorencent Cy3. or fIfCconjugxed secondary antbodies, Iespertuvety Arow indcate parvocellular CRH neurons containing VPimmuncwextivty. Single. labeled CRrtpositive cells are indk ated by artowheads. Scale bar $=100 \mu \mathrm{m}$ The imager are maximal projectron Z-stacks of stven (in A) and eight (in B) confocal sections separated by 1 um.

ACTH-IR has been also immunohistochemically studied in the postmortem hypothalamus and hippocampal formation in temporal lobe epilepsy patients |28|. In the present study, comprising by the cases with relatively similar postmortem period in control and CHF group. we observed a profound activation of CRH and ACTH expression in human patients afilicted with CHF. These facts are in line with the results from animal models of CHF, showing that in rats with ischemia-induced CHF the metabolic |29| and neuronal |30| PVN activity was increased. More specifically. CRH expression in the PVN was significantly elevated 


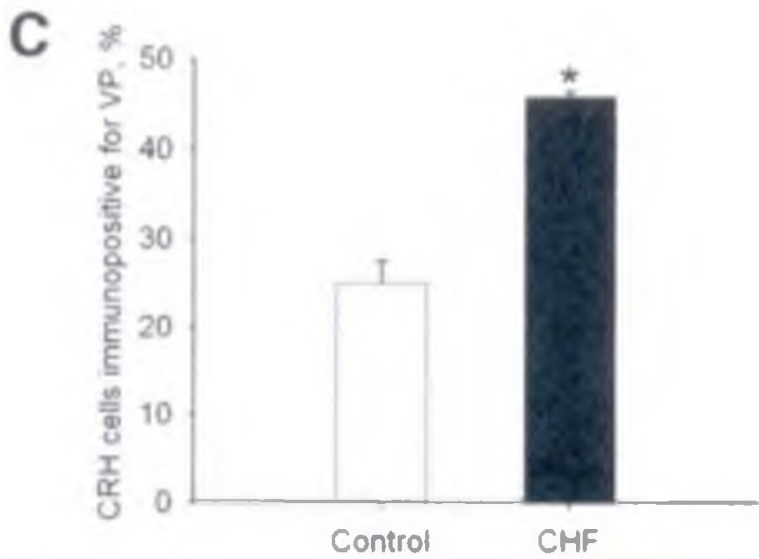

Fig. 2 (Continued) C: Proportion of CRHpositive neurons immunopositive for VP is strongly Inciesued in CHF patients. Croup mean values of the par ameters are ealculated hom individual mean values. "p<0.05 (t-test).

in ChF rats compared with sham-operated animals and CRH protein expression in hypothalamus was 1.9-fold higher in CHF than sham rats as indicated by immunohistochemistry and Western blot analysis | 18|. The increase in number of CRH neurons in the IVN was well correlated with the elevation of plasma ACTH [19]. All these observations are in agreement with our results in human patients with demonstrated elevation of CRH expression and increased numbers of CRH cells co-expressing VP, which potentiates effects of CRH on ACTH release [31]. Furthermore, results of the present study revealed not only a significant increase in the density of CRH neurons, but also an enhanced intensity of the staining in the PVN of CHF patients. These observations can serve as evidence for a drastic increase in CRH synthesis: according to recent reports a two-fold increase in CRH-IR cell number in the PVN of hypertensive patients corresponded to a five-fold elevation of CRH mRNA levels $[23,27]$. However, immunohistochemical technique applied to our study does not allow us to definitively conclude that basal CRH release into the portal blood is increased in CHF patients. Therefore, further measurements of CRH mRNA levels in the hypothalamus and CRH receptor type 1 mRNA levels in the pituitary of CHF patients will be required.

The upregulation of CRH and VP expression in CRH neurons and ACTH expression in the pituitary observed in our study predicted the elevation of cortisol in the blood. However, the level of cortisol in our CHF patients did not differ from the control group. and no rise of cortisol was found in patients with severe forms of CHF. These results are consistent with previous clinical data showing similar plasma cortisol concentrations in CHF patients and healthy subjects $|9|$ and the absence of correlation of cortisol levels with the hemodynamic parameters [10]. In contrast. several groups reported a significant elevation of cortisol in CHF purients comparrd to controls and a progressive increase of its concentrations commensurate with the functional class of CHF [13.14]. However, profound dystrophic changes in corticocytes of the zona fasculata. detected in our histological study of adrenal cortex. support recent comvincing dat a demonstrating either a normal range of cortisol concentrations in CHF patients [15) or even decreased levels of cortisol in some of CHF patients [12]. Furthermore our clinical and morphological results are in the line with the reported decline of cortisol responses to physical
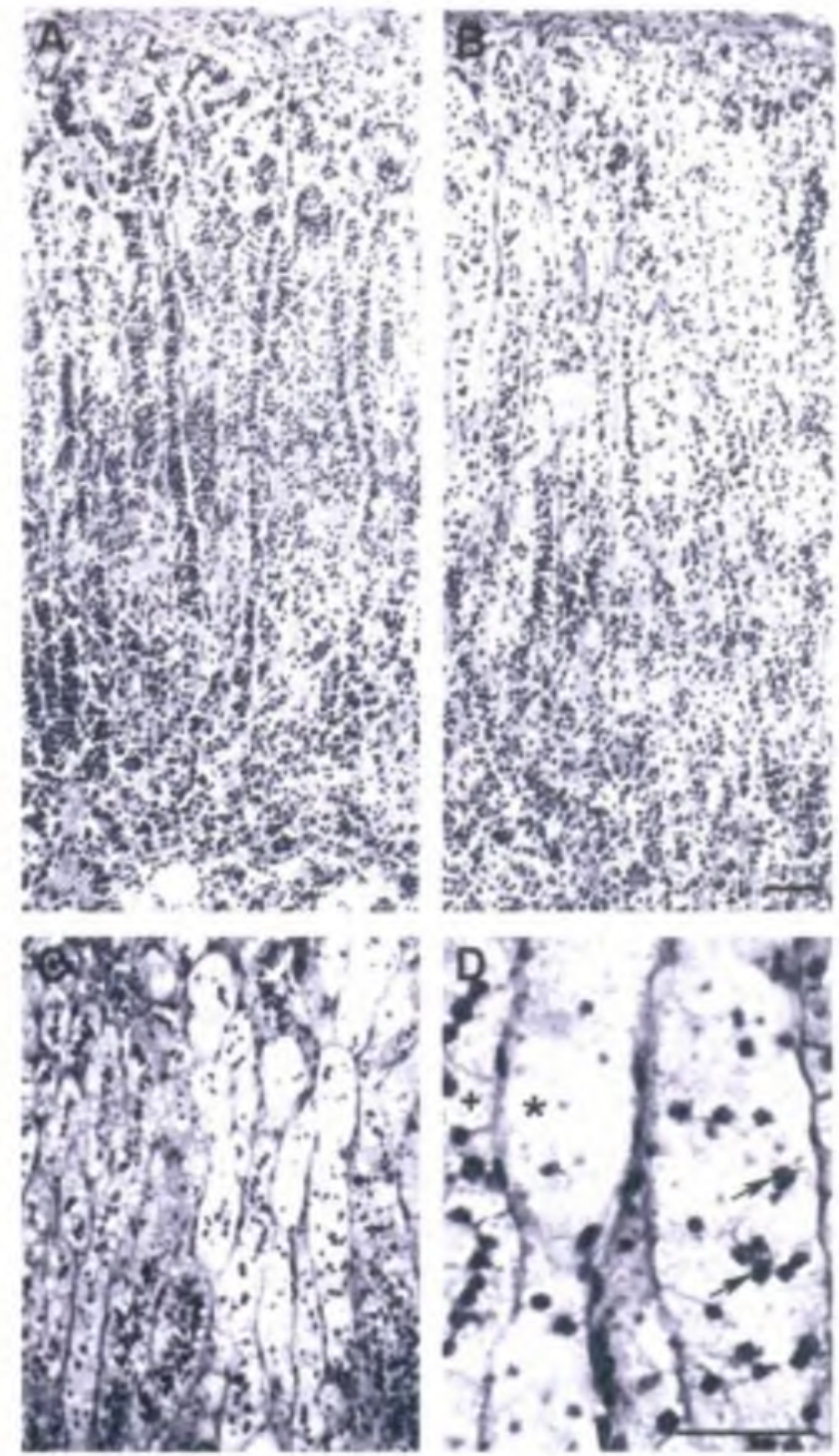

Fig. 3 Pathomorphological changes in the adrenal cortex. A: The structure of the adrenal cortex of the 65-year old control and 62-vear old CHt patients (B-D). A discomplexation of zona glomerulosa; diatic thinning. plethora and diapedesis in zona fasciculate (indicated by isterisk). C: Piotound vacuolsted dystrophy, pyknotsc changes in conticosyes of zona facleulata. D Erythrostmis, delipldation (big aterist: "normal" neighbouring tissue indicated by plus). pyknolic changes in cortacocytes (amows) of rona faxckulats. Staining with hemataryinecin. Scale bars - $100 \mu \mathrm{m}(\mathrm{A}, \mathrm{B}, \mathrm{C}), 50 \mu \mathrm{m}$ (0)

exercises in CHF patients (III). The lack of morphological evidence for adrenal cortex myperstimulation in CHF patients. as well as a normal basal cortisol levels coincided with increased ACTH-content in the pituitary may suggest several possibilities. such as the block of ACTH release from pituitary. decrease of sensitivity of adrenal cortex to ACTH, or interception of ACTH action with other modulators. To dissect these possible mechanisms. further studies of ACTH receptor expression in the adrenals as well as low-dose ACTH stimulation lest in CHF patients will be very informative.

The discrepancy between the CRH production and plasma gluco. corticoid levels has been observed in several human pathologies and some experimental models. For example. the elevation of CRH production without reported increase in plasma cortisol 
levels has been shown in alcoholics $|20,32|$ and patients with multiple sclerosis |26, 33|. In opposite. the elevated cortisol levels coincided with the unchanged hypothalamic CRH expression in patients with Alzheimer disease |34.35|. in animal models the discrepancy between CRH. ACTH. and corticosterone responses has been earliel observed in rats with chronic inflammation $|36|$. In these rats subjected to repeated injections of bacterial endotoxin lypopolysaccharide a prominent elevation of basal CRH expression and a trend for elevation of ACTH expression coincided with unchanged ACTH and corticosterone plasma leveis [6]. The dysregulation between the central and peripheral components of the HPA axis is a very important question, which will be addressed in our lurther studies with employment of in situ hybridisation technique for evaluation of CRH and ACTH receplors mRNA levels and performance of functional tests. such as very low-doses $\mathbf{A C T H}$ stimulation $|36|$ and dexamethasone suppression tests [37] with subsequent comparison of total and free fractions of plasma cortisol | 38| in CHF patients.

In conclusion, our siudy demonstrates that CHF patients exhibit the activation of hypothalamic and pituitary levels of the HPA axis but a failure of adrenal response and subsequent increase of systemic cortisol levels is noted. The unchanged plasma cortisol as well as severe morphological impairments of the adrenal cortex suggests that a primary adrenal locus is a principal site of the HPA axis dysregulation in CHF patients. The alteration of the adrenal cortex may lead to a mild (relative) deficiency of glucocorticoid production, which via feed-back signalling may lead to the upregulation of hypothalamic CRH expression in CHF patients.

\section{Ankweselesteremenes}

The authors thank Dr. Harold Gainer (NINDS, NIH, Bethesda, USA) for monoclonal antibody PS41 against vasopressin. Prof. Dr. Otto W. Witte for use of the microscopic facility in the Department of Neurology. Friedrich-Schillet University Jena. and Roswitha Kasch for technical assistance. E. S. was a recipient of DAAD short-term fellowship.

Department of Anatomy II, Frledrich Schiller Universily, Jend, Germamy Department of Faculty Therapy, Russian State Medical University. Moscow, Russia

Depar tment of Pathology. Regiunal Hosplt al. Betgorod. Russia Reglonal Mrdic al E eperi Bureau ul Medical Legal Examination, Kaliningrad. Russi:

Department of Molecular Neurobiology, Mas-Planck-Institute for Medical Research. Heidelberg. Germany

\section{Hivierentes}

I Soro Y. Mivamoto T, Taniguchi R. Nishio Y. Rito T. Fuliwara H. Takotsu V. Current understanding of biochernical markers in heart failure. Med Sci Moni 2006: 12: RA252-RA264

2 Pocter $M$ How should physicians view heart failure?. The philosophic al and physiological evolution of three conceptual models of disease Am J Cardial 1993: 71: 3C-11C

3 Froncis CS. Pathophysiolugy of chronic heart failure. Ann ] Med 2001: 110 (Suppl 7A): 37S-46S

4 kotg Mingurll E Clinical use of markers of neurohormonal activation in heart failure. Rev Esp Cardiol 2004: 57: 347-356

$5 \mathrm{Scoft} U V$, Dinan $T C$. Vasopressin and the regulation of hypothalamicpituitary adrenal axis function: implications for the pathophysiology of depression. Life Sci 1998; 62: 1985-1998
6 Grinevich $V$, Ma X-M, Vlerman J. Jezovo D. Akmayev I. Azuilera C. Cfiect of repeated lipopolysaccharide administration on tissue cytokine expression and hypothalamic-pituitury-adrenal axis activity in ials. J Neuroendocrinol 2001: 13: 711-723

7 Lightmon SL. Windle RJ. Mo XM. Harbuz MS, Shonks NM. Julian MD, Wood SA, Kershaw YM. Ingram CD. Hypothalamic-pituitary-adrenal Iunction. Arch Mhysiol Bioxhem 2002; 110: 90-93

8 Asuilero C. Regulation of pituitary ACIM secretion during chronic stress. Front Neuroendocrinol 1994: 15: $321-350$

9 sito $K, K u b o$ S, Soimyoji $H$. Role of endocrine factors in chronic congestive heart failure, with emphasis on caterholamines. Jpn Circ | 1980; 4: 117-127

10 Morijama Y. Yasue H. Yoshimura M. Miruno Y. Nishivamo K. Tsunudo R. Kawuno H. Kugivama K. Oguwa H. Saitu Y. Nakoo K. The plasma levels of dehydroepiandrosterone sulfate ate derieased in patients with chronic heart failure in propurtion to the severity. I Clin Endo. crinol Melab 2000: 85: 1834-1840

II Labzeva V, Rylowa AK. Zhemerikina EV, Novikov IE. Adaptive reserves of the myorardium in patients with ischemic heart disease. Kardiologica 1990: 30: 22-24

12 Lu L. L W WM. Clinical significance of the function of adrenal cortex in refractory congestive heart lailure. Zhongguo Wei Zhung Bing Ji Jiu $Y_{1}$ Xue 2003: 15: 489-491

13 Collino 5. Prosperino C. Di Giovinni P. Caela F. Dy Napuli P. Caelu MA. Muzil $C$. Borsolfi A. The prognostic value of activation of the hypophyseal and adrenal cortical systems in severe heart failure Cardio. logid 1997: 42: 77-82

14 Emdin M. Possino C. Proniera C. Jervasi A. Ripoll A, Masini S, Jucchrll CC. Clerico A. Candiac natriuretic hormones, neuro-hormones, thyroid hop mones and cytokines in normal subjects and patients with heart failure. Clin Chem Lab Med 2004; 42: 627-636

is Guder C. Bauersachs J, Franlz S, Weismann D. Allolio B. Erul G. Angermann CE, Stork $S$. Complementary and incremental mortslity risk prediction by cortisol and aldosterone in chronic heart lailure CireuIation 2007: 115; 1754- 1761

16 Von Couter E, Leproult R. Kupfer Dy Efierts of gendet and age on the levels and circadian hythmicity of plasma rortisol. J Clin Endocrinol Metab 1996: 81 : 2468-2473

17 Kasatkino IV. Pivovarov VN. Markovo EV. Salem S. Roxset's AN Blood hormones in chronic ischemic heart disease and acute myocardial infarct. Kardiologiid 1979; 19: 93-98

18 Kang YM. Zhong ZH. Johnson RF, VU V. Reltz T. Johnson AK. Wriss RM, Felder RB. Novel effect of mineralocorticoid receptor antagonism to reduce proinflammatory cytokines and hyporhalamic activation in rats with ischemia-induced heart failure. Circ Res 2006; 99: 758-766

Is Kang YM. Zhang ZH, Xue B, Weiss RM, Felder RE. Inhibition of brain proinilammatory cytokine synthesis reduces hypothalamic excilation in rats with ischemia-induced heart fallure. Am J Hhysiol Heart Core Physiol 2008, 295: H227-H236

20 Sivukhino EV, Dolzhikov AA. Morazov luE, Jirikowski GF, Grinevich V. Effects of chronic alcoholic disease on magnocellular and parvocellular hypothalamic neurons in men. Horm Metab Res 2006; 38: $382-390$

21 Ben-Barak Y. Russel T, Whitnal MH. Ozoto K, Cainer II. Neurophys in in the hypothalamo-neurohypophysed system. I. Production and characterization of monoclonal antibodies. I Neurosci 1985: 5: 81-97

22 Whitnall MH, Key $S$, Ben-Earak $Y$, Uzato $K$. Cainer $/ 1$ Neurophysin in the hypothalamo-neurohypophyseal system. II. Immunohistochemi cal studies of the ontogeny of oxytocinergic and vasopressinergic neurons. J Neurosci 1985; 5: 98-109

23 Concharak VD. Von Heerikhuize J. Swaob DF, Buijs RM. Paraventricular nucleus of the human hypothalamus in primary mypertension: activa tion of corticotropin-relessing hormone ncurons. J Comp Neurol 2002: 413: $321-33$ i

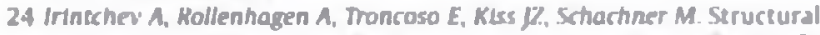
and functional aberrations in the cerebral cortex of tenascin- $C$ deficient mice. Cereb Cortex 2005: 15: 950-962

25 thadsheer A. Hoogendijk W. Stom AC. Tilders F). Swoob DF. Incredurd numbers of corticotrophin-releasing hormone expressing neurons in the hypothalamic paraventricular nucleus of depressed patients. Neuroendocrinology 1994: 60: 436-444

26 Purba JS, Roadsheer $R$. Hofmon MA. Ravid R. Aolman CH. Komphorst W. Swaab DF Increased number of corncotropin-releasing hormone expressing neurons in the hypothalamic paraventricular nucleus of patients with multiple sclerosis Neuroendocrinology. 1995: 62: $62-70$ 
27 Concharuk VD, Buijs RM, Swoab of. Corticotropin-releasing hormone neumns in hypertensive patients are activated in the hypothaldmus but not in the brainstem. J Comp Neurol 2007; 503: 148-168

28 Iynd-Balta E. Pilcher WH. Joseph SA. Adrenocorticotropic hormone immunoreactivity in the hippocampal formation of temporal lobe epilepsy patients. Epilepsia 1996; 37: $1081-1087$

24 Fotel KP, Thong $P L$, Krukof $r L$ Alterations in brain hexokinase activity associated with heart fallure in rats. Am J Physiol 1993; 265: R923R928

30 Zhang $2 H$, Fronds J, Weiss RW, Felder RB. The renin-angiotensin-aldosterone system exciles hypothalamic paraventricular nucleus neurons in heart faflure. Am J Physiol Heart Círc Physiol 2002, 283: HA23H433

31 Agullera C. Pham O kabadan-Dichl C. Regulation of pituitary vasopressin receptors during chronic stress: relationship to corticotroph responsiveness. I Neuroendocrinol 1994; 6: 299-304

32 Wand CS. Dobs AS. Alterations in the hypothalamic-pituitary-adrenal axis in actively dnnking alcoholics / Clin Endocrinol Metab 1991; 72 : $1290-1295$

33 Zych-Twardowska E. Wajgt A. Blood levels of selected hormunes in patients with multiple sclerosis. Med Sci Monit 2001: 7: 1005-1012
34 Swaob DF, Raadsheer F. Endert E. Hofman MA, Kamphorst W, Ravid $\boldsymbol{R}$. Increased cortisol leveis in aging and Alzheimer's disease in posemortem cerebrospinal fluid. J Neuroendocrinol 1934; 6: 681-687

35 Raodsheer FC. Oorschot DE. Verwer RW, IIlders F. Swaob Df Agc related increase in the total number of corticotropin-releasing holmone neurons in the human paraventricular nucleus in controls and Alzheimer's disease: comparison of the disector with an unfolding method. J Comp Neurol 1994; 339: 447-457

36 Dickstein G, Shechner C. Nicholson WE. Rosner I, Shen-Orr Z Adowi F. Lahov M. Adrenocorticotropin stimulation test: effects of basal cortisol level, time of day, and suggested new sensitive low dose test. J Clin Endocrinol Metab 1991; 72: 773-778

37 Silva IS, Longui CA, Faria CD. Rocha MN. Melo MR, faria TC. de Souza E Almeida /A. Mayashi Lf, Kater CE. Impact of prolonged physical ttaining on the pituitary glucocorticoid sensitivity determined by very low dose intravenous dexamethasone suppression test. Horm Metab Res 2008; 40: 718-721

38 Torpy 0 , Ho $\int$. Value of free cortisol measurement in systemic infer tion. Horm Metab Res 2007: 39: 439-444 